\title{
Knowledge and Awareness about Leishmaniasis Disease in the General Public of Quetta, Pakistan
}

\author{
Tanzeel Ahmed ${ }^{1,2}$, Sarmad Sheraz Jadoon ${ }^{1}$, Muhammad Waqas ${ }^{3}$, Muhammad Ammar ${ }^{4}$, Liguo Jian ${ }^{5}$, Qi Zhang ${ }^{5, *}$ \\ ${ }^{1}$ State Key Laboratory of Esophageal Cancer Prevention \& Treatment, School of Pharmaceutical Sciences, Zhengzhou University, \\ Zhengzhou, CHINA. \\ ${ }^{2}$ Bolan Medical Complex Hospital, Quetta, PAKISTAN. \\ ${ }^{3}$ Department of Pharmacology and Therapeutics, Bolan University of Medical \& Health Sciences, Quetta, PAKISTAN. \\ ${ }^{4}$ Internal Medicine, Gulab Devi Hospital, Lahore, PAKISTAN. \\ ${ }^{5}$ The Second Affiliated Hospital of Zhengzhou University, Zhengzhou, CHINA.
}

\section{Received: 14 Jan 2021; \\ Accepted: 21 Mar 202 \\ *Correspondence to:}

Qi Zhang,

The Second Affiliated Hospital of Zhengzhou University, Zhengzhou, Henan Province,450052,

P.R, CHINA.

Email:qizhang@zzu.edu.cn Copyright: (C) the author(s),publisher and licensee Indian Academy of Pharmacists. This is an open-access article distributed under the terms of the Creative Commons Attribution Non-Commercial License, which permits unrestricted non-commercial use, distribution, and reproduction in any medium, provided the original work is properly cited.

\begin{abstract}
Aim: This study attempted to assess knowledge and awareness about Leishmaniasis disease in Quetta city, Pakistan. Materials and Methods: This was a questionnaire-based cross-sectional survey where 387 study respondents were targeted using the non-probability convenience sampling method for data collection. SPSS $\checkmark 22.0$ was applied for data analysis and $P \leq 0.05$ was considered statically significant. The Mann-Whitney and Kruskal-Wallis tests were performed to discover the relationship among variables. Results: Most respondents were from the age group 18-27 years 269 (69.5\%) majority of whom were female 244 (64.0\%). Most of the respondents had improved knowledge (73.6\%), about the word Leishmaniasis, $50.6 \%$ of respondents were aware of the signs and symptoms, $54.8 \%$ of respondents were aware of the diagnosis, $64.3 \%$ of respondents had improved knowledge about treatment, $62.5 \%$ of the study population were aware of prevention and $40.8 \%$ of study respondents knew about the vaccination for leishmaniasis. Conclusion: This study exposed an overall better knowledge and awareness among the public about leishmaniasis disease and its causative agents, symptoms, diagnosis, treatment, prevention, and vaccination.
\end{abstract}

Key words: Knowledge, Awareness, Leishmaniasis disease, Public, Quetta, Pakistan.

\section{INTRODUCTION}

Leishmaniasis is a subtropical and tropical disorder produced by an intracellular protozoan (Leishmania) transmitted into the human body through the bite of female Phlebotomus, P. sergenti, and P. salengensis sand flies in Asia, North America, and some regions of South America, the Middle East, Europe, and North Africa..$^{[1]}$ Leishmaniasis has complicated and diverse epidemiology. Leishmaniasis is amongst those essential tropical disorders which cause serious health problems. The World Health Organization suggested that over (147 million) humans in the South-East Asia area are prone to Leishmania parasites that cause (kala-azar), a life-threatening disorder. ${ }^{[2]}$ According to WHO, every year, 300,000 new cases are reported $90 \%$ of which are from Ethiopia, Sudan, Bangladesh, India, and Brazil. ${ }^{[3]}$ The life cycle of Leishmania consists of two hosts: Leishmania parasites exist as extracellular promastigotes in the sand fly, and as intracellular amastigotes in the host. ${ }^{[4]}$ Almost 20 species of leishmania that cause infection in humans are recognized as leishmaniasis. Promastigotes development takes place in the intestines of sandflies which inject these into human skin. Promastigotes are long free flagellum. Inside the human skin, promastigotes are injected by way of the reticuloendothelial system, alternating into spherical shape i.e., amastigote and do not have visible flagella. Amastigote then multiplies to structure phagolysosomes and causes primary lesion at the bitten region. Infection is frequently spread through the lymphatic system and causes secondary dermal lesion with types and tissue tropisms in human beings. ${ }^{[5]}$ The length of the sand-fly is about $3 \mathrm{~mm}$, with large and darkish eyes, lengthy antennae directed downward, and additionally have long and delicate legs characterized as hopping flight. ${ }^{\left[{ }^{[]}\right.}$Sandflies are sensitive to dehydration and are nocturnal. They stay in caves, tree holes, rocks, and human rooms. Female and male sandflies feed nectar from flowers, plant juices, and fruits. Carbohydrates are the source of energy. A blood meal is sucked by the female flies to complete the development of eggs. ${ }^{[7]}$ The cutaneous leishmaniasis epidemic is related to that activity in which human beings interrupt the environment of the vector through road construction and deforestation. Travelling, army exercises, and immigration are likely to increase the spread of leishmaniasis around the globe. ${ }^{[8,9]}$ In Pakistan, cutaneous leishmaniasis and visceral leishmaniasis, and the discovery of new foci have been often reported in different areas of Khyber Pakhtunkhwa, Azad Kashmir, and Baluchistan. ${ }^{[10,11]}$ Many patients have been identified with cutaneous leishmaniasis in Somniani which is the coastal region of Balochistan about $70 \mathrm{~km}$ away from Karachi city. ${ }^{[12]}$

Patients were also reported from Chakwal, Dera Ghazi Khan, and the Multan region of Punjab province. ${ }^{[13]}$ Cutaneous Leishmaniasis is frequent in Afghan refugee camps in Dir and Timergera district of Khyber Pakhtunkhwa province. Cutaneous Leishmaniasis is endemic in the Pak-Afghan border belt region. Cutaneous Leishmaniasis has been frequent among Afghans over the years. This disorder is recognized as "saal dana" in Afghanistan (saal means year and dana mean lesion). ${ }^{[14]}$ During the Soviet-Afghan conflict, a massive number of Afghan human beings migrated to Kurram refugee camp placed near the border region (FATA) where they infected a large population ${ }^{[15]}$ in the nearby areas as well. ${ }^{[16]}$ The knowledge of vector biology and ecology is crucial in planning a positive method to manage leishmania 
regions. These types of research work have been ignored in specific regions of Khyber Pakhtunkhwa. Eco-epidemiological research of leishmaniasis requires statistics about the abundance and variety of sand flies as well as their role as vectors in the concerned location. ${ }^{[17]}$ Community input is the most vital requirement for successful control and prevention programs of any disease, and collaboration of the infected humans is critical for the application and use of control program actions. ${ }^{[18,19]}$ Therefore, researchers want to understand the extent of recognition among the public about or their expertise on leishmaniasis and its associated signs and symptoms, diagnosis, treatment, and preventive practices because these are essential determinants of community participation. The existing study is therefore undertaken to check the knowledge and awareness about leishmaniasis in the public in this context.

\section{MATERIALS AND METHODS}

A cross-sectional survey-based study was conducted at Quetta, Pakistan from May-2018 to October-2018.

\section{Sample size and technique selection criteria}

A total number of 387 study respondents of more than 18 years of age were focused on the non-probability convenience sampling technique by a trained interviewer. Study respondents who had different medical problems or were incapable to reply to a shortlist of easy queries (socio-demographic information), such as an address, name, complications due to disease) were disqualified from the study.

\section{Data collection}

A two-part interviewer-administered questionnaire was used for evaluating the knowledge and awareness about leishmaniasis in Quetta, Pakistan. Part I had a provision to accumulate demographic statistics as follows, age, gender, qualification, occupational status, and monthly income. Part II contained 21 questions in different sections about knowledge and awareness concerning leishmaniasis. A questionnaire with open questions was used in the pilot study for twenty-five individuals as pre-testing to validate the questions. The result of the pilot study was not considered. Based on their responses, the final questionnaire was formulated. The final questionnaire was organized and closed-ended. The interview was conducted, and responses were cited in the survey form.

\section{Management and statistical analysis}

Throughout the data-collection procedure, statistics were checked for completeness, and all the incomplete or unfilled questionnaires were excluded from the study. The frequencies and percentages were considered. The MannWhitney and Kruskal-Wallis tests were carried out to discover the relationship amongst variables. The $P \leq 0.05$ was considered statically significant. This data was assessed by using SPSS 22.

\section{RESULTS}

\section{Demographic characteristics of the general public}

A total of 387 study respondents were interviewed of which most were female $244(64.0 \%)$. Most of the study respondents belonged to the age group 1827 years $269(69.5 \%)$. The qualification of most of the study respondents was intermediate $116(30.0 \%)$, a lot of them were unemployed $189(48.8 \%)$, and most preferred not to disclose their monthly income $206(53.2 \%)$ as described in Table 1.

\section{Knowledge and awareness about leishmaniasis disease}

Different questions had been asked about; signs, symptoms, diagnosis, treatment, prevention, and vaccination as described in Table 2 , as follows.

\section{General knowledge and awareness}

Most of the study respondents had improved knowledge. When asked; (1) have you ever heard about leishmaniasis? $73.6 \%$ of the study respondents agreed, $22.0 \%$ disagreed, and the remaining 4.4\% replied: "I don't know". When asked (2) "Sand flies cause leishmaniasis disease?" 66.9\% agreed, about $19.4 \%$ replied "I don't know" and 13.7\% disagreed. Most of the respondents agreed up to $63.8 \%$ while responding to the declaration (3) "Leishmaniasis cause wound on the face or lower limb "The remaining $21.2 \%$ were unaware and $15.0 \%$ disagreed.

\section{Sign and symptoms}

Queries were made about signs and symptoms: (1) "Fever, weight loss, and loss of appetite are the symptoms of leishmaniasis" $50.6 \%$ agreed, about $27.9 \%$ were unaware and $21.4 \%$ disagreed; (2) "Having a wound on site of the fly bite is a symptom" $58.1 \%$ of respondents agreed, $22.7 \%$ responded "I don't know" and 19.1\% disagreed; (3) "Normally, the sand-fly bites in the morning or in the evening time" $49.4 \%$ of respondents agreed, $31.5 \%$ were unaware and $19.1 \%$ disagreed.

\section{Diagnosis}

These questions were asked about the analysis of leishmaniasis: (1). "Analysis of a sample taken from a wound diagnosed with leishmaniasis" Only $54.8 \%$ of respondents agreed, $26.9 \%$ answered "I don't know", and 18.3\%

\section{Table 1: Demographic characteristics of the general public.}

\begin{tabular}{|l|l|}
\hline Description & $\mathbf{N}(\%)$ \\
\hline Gender & \\
Male & $143(37.0)$ \\
Female & $244(63.0)$ \\
\hline Age Group & \\
$18-27$ & $269(69.5)$ \\
$28-37$ & $70(18.1)$ \\
$38-47$ & $27(7.0)$ \\
$48-57$ & $5(1.3)$ \\
58 and above & $16(4.1)$ \\
\hline Qualification & $39(7.5)$ \\
Illiterate & $22(5.7)$ \\
Religious only & $23(5.9)$ \\
Primary & $66(17.1)$ \\
Matric & $116(30.0)$ \\
Intermediate & $58(15.0)$ \\
Graduate & $73(18.9)$ \\
Others & \\
\hline Occupation & $189(48.8)$ \\
Unemployed & $38(9.8)$ \\
Government Servant & $42(10.9)$ \\
Private Servant & $92(23.8)$ \\
Self Employed & $26(6.7)$ \\
Housewife & \\
\hline Income in (PKR) & $53(13.7)$ \\
<10000 & $33(8.5)$ \\
10001-20000 & $29(7.5)$ \\
20001-30000 & $66(17.1)$ \\
30001 \& & $206(53.2)$ \\
Not want to tell & \\
\hline PKR=Pakistan Rupees & \\
\hline & \\
\hline
\end{tabular}


disagreed; (2). "Blood test is necessary for the diagnosis of leishmaniasis", $58.9 \%$ of respondents agreed, $23.8 \%$ responded "I don't know", and $17.3 \%$ disagreed.

\section{Treatment}

Questions asked about the cure of leishmaniasis were: (1) "Treatment of Leishmaniasis is available" $64.3 \%$ of respondents agreed, $21.4 \%$ replied "I don't know", and 14.2\% disagreed; (2) "Treatment of leishmaniasis is available in our city" $62.3 \%$ of the respondents agreed, $22.5 \%$ responded "I

\begin{tabular}{|c|c|c|c|}
\hline Questions & $\begin{array}{l}\text { Agree } \\
\mathrm{N}(\%)\end{array}$ & $\begin{array}{l}\text { Disagree } \\
\mathrm{N}(\%)\end{array}$ & $\begin{array}{l}\text { I do not } \\
\text { Know } \\
\text { N (\%) }\end{array}$ \\
\hline \multicolumn{4}{|l|}{ I. General knowledge and awareness } \\
\hline $\begin{array}{l}\text { Have you ever heard about } \\
\text { leishmaniasis? }\end{array}$ & $285(73.6)$ & $85(22.0)$ & $17(4.4)$ \\
\hline $\begin{array}{l}\text { Mosquitoes bite is the main cause of } \\
\text { leishmaniasis disease }\end{array}$ & $236(61.0)$ & $88(22.7)$ & $63(16.3)$ \\
\hline $\begin{array}{l}\text { Sandflies cause of leishmaniasis } \\
\text { disease? }\end{array}$ & $259(66.9)$ & $53(13.7)$ & $75(19.4)$ \\
\hline $\begin{array}{l}\text { Can you differentiate between sand } \\
\text { flies and common house flies or } \\
\text { mosquitoes? }\end{array}$ & $181(46.8)$ & $141(36.4)$ & $65(16.8)$ \\
\hline $\begin{array}{l}\text { Leishmaniasis can be caused by } \\
\text { skin only }\end{array}$ & $238(61.5)$ & $74(19.1)$ & $75(19.4)$ \\
\hline $\begin{array}{l}\text { Leishmaniasis affects other parts of } \\
\text { the body }\end{array}$ & $208(53.7)$ & $88(22.7)$ & $91(23.5)$ \\
\hline $\begin{array}{l}\text { Leishmaniasis cause wound on the } \\
\text { face or lower limb }\end{array}$ & $247(63.8)$ & $58(15.0)$ & $82(21.2)$ \\
\hline $\begin{array}{l}\text { Leishmaniasis can harm internal } \\
\text { organs like the Liver }\end{array}$ & $184(47.5)$ & $111(28.7)$ & $92(23.8)$ \\
\hline \multicolumn{4}{|l|}{ II. Sign and symptoms } \\
\hline $\begin{array}{l}\text { Fever, weight loss, and loss of } \\
\text { appetite are the symptoms of } \\
\text { leishmaniasis }\end{array}$ & $194(50.6)$ & $83(21.4)$ & $108(27.9)$ \\
\hline $\begin{array}{l}\text { Having a wound on site of the fly } \\
\text { bite is a symptom }\end{array}$ & $225(58.1)$ & $74(19.1)$ & $88(22.7)$ \\
\hline $\begin{array}{l}\text { Normally, the sand-fly bites in the } \\
\text { morning or in the evening time }\end{array}$ & $191(49.4)$ & $74(19.1)$ & $122(31.5)$ \\
\hline \multicolumn{4}{|l|}{ III. Diagnosis } \\
\hline $\begin{array}{l}\text { Analysis of a sample taken from a } \\
\text { wound diagnosed with leishmaniasis }\end{array}$ & $212(54.8)$ & $71(18.3)$ & $104(26.9)$ \\
\hline $\begin{array}{l}\text { The blood test is necessary for the } \\
\text { diagnosis of leishmaniasis }\end{array}$ & $228(58.9)$ & $67(17.3)$ & $92(23.8)$ \\
\hline \multicolumn{4}{|l|}{ IV. Treatment } \\
\hline $\begin{array}{l}\text { Treatment of leishmaniasis is } \\
\text { available }\end{array}$ & $249(64.3)$ & $55(14.2)$ & $83(21.4)$ \\
\hline $\begin{array}{l}\text { Treatment of leishmaniasis is } \\
\text { available in our city }\end{array}$ & $241(62.3)$ & $59(15.2)$ & $87(22.5)$ \\
\hline $\begin{array}{l}\text { Injection at the wound site one of the } \\
\text { treatments for Leishmaniasis }\end{array}$ & $240(62.0)$ & $60(15.5)$ & $87(22.5)$ \\
\hline \multicolumn{4}{|l|}{ V. Prevention } \\
\hline $\begin{array}{l}\text { Flypapers can be used to control } \\
\text { sand flies }\end{array}$ & $239(61.8)$ & $69(17.8)$ & $79(20.4)$ \\
\hline $\begin{array}{l}\text { Insecticides sprays can be used to } \\
\text { control sand flies }\end{array}$ & $242(62.5)$ & $65(16.8)$ & $80(20.7)$ \\
\hline $\begin{array}{l}\text { Insect repellents can be used to } \\
\text { control sandflies }\end{array}$ & $228(58.9)$ & $70(18.1)$ & $89(23.0)$ \\
\hline \multicolumn{4}{|l|}{ VI. Vaccination } \\
\hline Is there any vaccination available? & $158(40.8)$ & $114(29.5)$ & $115(29.7)$ \\
\hline
\end{tabular}

don't know", and $15.2 \%$ disagreed; (3) "Injection at the wound site one of the treatments of Leishmaniasis" $62.0 \%$ of the respondents agreed, $22.5 \%$ responded "I don't know", and 15.5\% disagreed.

\section{Prevention}

Multiple questions were asked in this part: (1) "Flypapers can be used to control sand flies" $61.8 \%$ of the respondents agreed, $20.4 \%$ replied "I don't know", and $17.8 \%$ disagreed; (2) "Insecticides sprays can be used to control sand flies" $62.5 \%$ of the respondents agreed, $20.7 \%$ answered "I don't know", and $16.8 \%$ disagreed. (3) "Insect repellents can be used to control sandflies" $58.9 \%$ of the respondents agreed, $23.0 \%$ answered "I don't know", and $18.1 \%$ disagreed.

\section{Vaccination}

To the query, "Is there any vaccination available?", $40.8 \%$ of the respondents agreed, $29.7 \%$ replied "I don't know", and the remaining 29.5\% disagreed, as described in Table 2.

\section{Source of information}

Most of the study respondents said that they heard about leishmaniasis from their friends, family, and relatives $39.8 \%$, followed by newspapers, tv, radio, $33.6 \%$, doctors $26.4 \%$, and others $0.3 \%$ as described in Figure 1.

\section{Association among study variables and survey objects}

The association between the questionnaire and demographics were calculated. Mann-Whitney, and Kruskal-Wallis tests were performed to check the static significance using SPSS 22, as Table 3.

\section{DISCUSSION}

Understanding the stage of common knowledge and awareness about any communicable or non-communicable disease is a primary step in enforcing

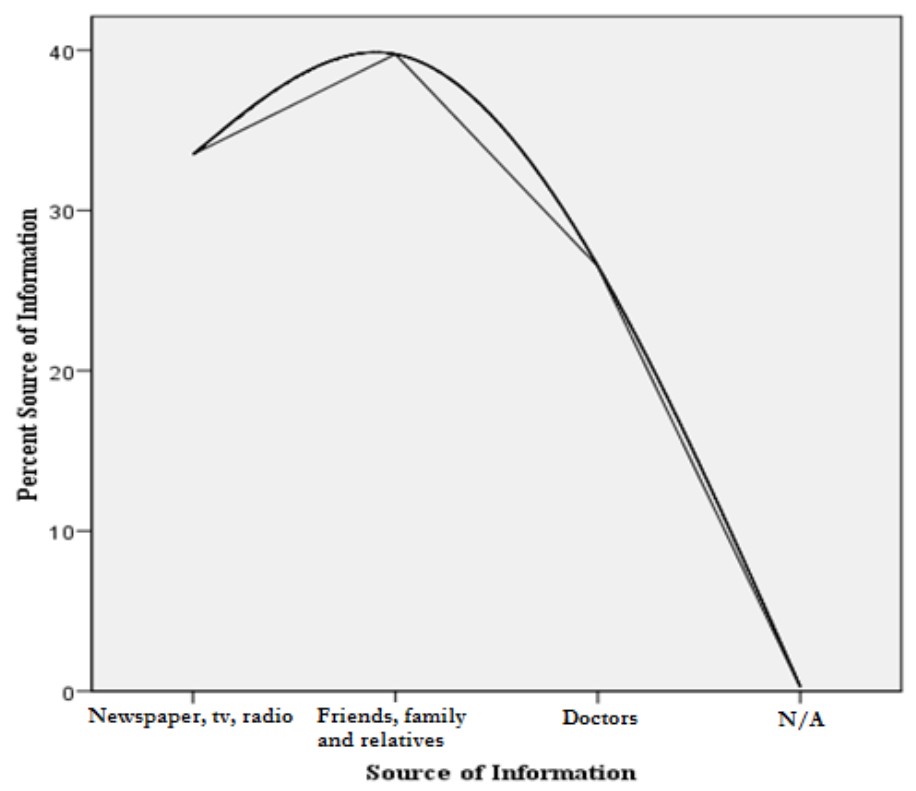

Figure 1: Source of information; the percentage of newspapers, tv, radio $(33.5 \%)$, friends, family, relatives $(39.8 \%)$, doctors $(26.5 \%)$, and N/A $(0.3 \%)$ are shown in interpolation line. 
inhibition programs positively. The primary objective of this study was to verify the knowledge of leishmaniasis disease signs and symptoms, diagnosis, treatment, prevention, and vaccination status among the public and to identify the gaps in their expertise to improve future health education programs. The majority of the study respondents had improved knowledge about phrase Leishmaniasis reason for Leishmaniasis disease and Leishmaniasis can be triggered on the skin only. ${ }^{[20,21]}$ The existing study shows equal results. But the study was carried out in the manner of Mebrahtu et al. who cited that all the study respondents were aware of the leishmaniasis disease. ${ }^{[22]}$ But in the present study, most of the study respondents were aware, not all. Most respondents answered "no" to the query, "can you differentiate between sand flies and common houseflies or mosquitoes?". Most were unaware when asked, "Do you understand the biting time of sand flies?", "do you know symptoms of the disease?" and "do you understand the control methods of sand flies?". ${ }^{[23]}$ But in the present study, most respondents responded positively to these against the pattern seen in Ayesha et al. A study NA Siddiqui et al. was asked its respondents about signs and symptoms. The majority recognized "fever" as a sign and a symptom, and only $13.5 \%$ were aware of "loss of appetite" as a symptom. ${ }^{[18]}$ But in the existing study, to the query, "fever, weight loss and loss of appetite are signs or symptoms of leishmaniasis?", the majority was aware of the signs and symptoms, and
$27.9 \%$ was unaware. NA Siddiqui et al. also asked if "complete treatment of the disease is possible". The majority was aware, $4.6 \%$ answered "no", and only $0.4 \%$ replied "I don't know". ${ }^{[18]}$ In contrast, the present study asked, "is the treatment of leishmaniasis available?". The majority was aware, $21.4 \%$ answered "I don't know", and 14.2\% were unaware. In the same context, it was asked, "Is the treatment of leishmaniasis is available in our city?" The majority answered "yes", 22.5\% replied "I don't know", and only 15.2\% responded "no". The results of NA Siddiqui et al. and the present study almost had similar results because improved knowledge and awareness were recorded in both. However, there are some dissimilarities as well.

In a study conducted in Nepal, the researcher observed that no one knew how the disease could be prevented. ${ }^{[24,25]}$ However, NA Siddiqui discovered that the majority of respondents did now not know about prevention measures, and only $20 \%$ used mosquito nets as a prevention measure. ${ }^{[18]}$ But in the current study, different questions were asked about preventive measurements which include: (1) can flypapers be used to control sand flies? The majority (61.8\%) was aware and only $20.4 \%$ did not know; (2). "Insecticide sprays are used to control sand flies" A majority had improved knowledge about prevention, and only $20.7 \%$ of respondents were unaware: (3). Can insect repellents be used to manipulate sandflies? Majority was aware and only $23.0 \%$ were unaware.

Table 3: Association among study variables and survey objects.

\begin{tabular}{|c|c|c|c|c|c|}
\hline Questions & Age $^{a}$ & Gender ${ }^{a, b}$ & Education $^{a}$ & Occupation $^{a}$ & $\begin{array}{l}\text { Income }^{\mathrm{a}} \\
\text { PKR }\end{array}$ \\
\hline Mean \pm Standard Deviation & $27.64 \pm 11.34$ & $1.64 \pm .48$ & $4.76 \pm 1.74$ & $2.28 \pm 1.43$ & $3.87 \pm 1.47$ \\
\hline \multicolumn{6}{|l|}{ I. General knowledge and awareness } \\
\hline Have you ever heard about leishmaniasis? & $.128^{*}$ & $.189^{*}$ & $.298^{*}$ & $.327^{\star}$ & $.400^{*}$ \\
\hline Mosquitoes bite is a main cause of leishmaniasis disease & $.004^{\star *}$ & $.208^{*}$ & $.000^{* *}$ & $.364^{*}$ & $.059^{*}$ \\
\hline Sandflies cause of leishmaniasis disease? & $.004^{* *}$ & $.339^{*}$ & $.345^{*}$ & $.145^{*}$ & $.563^{*}$ \\
\hline $\begin{array}{l}\text { Can you differentiate between sand flies and common house flies or } \\
\text { mosquitoes? }\end{array}$ & $0.0^{* *}$ & $.209^{*}$ & $.048^{*}$ & $.014^{*}$ & $.644^{*}$ \\
\hline Leishmaniasis can be caused by skin only & $.213^{*}$ & $.745^{*}$ & $.002^{* *}$ & $.690^{*}$ & $.582^{*}$ \\
\hline Leishmaniasis affect other parts of the body & $.197^{*}$ & $.285^{*}$ & $.116^{*}$ & $.405^{\star}$ & $.752^{*}$ \\
\hline Leishmaniasis cause wound on the face or lower limb & $.011^{* *}$ & $.696^{*}$ & $.090^{*}$ & $.303^{*}$ & $.824^{*}$ \\
\hline Leishmaniasis can harm internal organs like the Liver & $.339^{*}$ & $.041^{* *}$ & $.002^{* *}$ & $.027^{\star}$ & $.795^{*}$ \\
\hline \multicolumn{6}{|l|}{ II. Sign and symptoms } \\
\hline $\begin{array}{l}\text { Fever, weight loss, and loss of appetite are the symptoms of } \\
\text { leishmaniasis }\end{array}$ & $.461^{*}$ & $.305^{*}$ & $.155^{*}$ & $.291^{*}$ & $.977^{\star}$ \\
\hline Having a wound on site of the fly bite is a symptom & $.571^{*}$ & $.223^{*}$ & $.000^{* *}$ & $.397^{\star}$ & $.322^{*}$ \\
\hline Normally, the sand-fly bites in the morning or in the evening time & $.263^{*}$ & $.774^{*}$ & $.048^{*}$ & $.417^{\star}$ & $.705^{*}$ \\
\hline \multicolumn{6}{|l|}{ III. Diagnosis } \\
\hline $\begin{array}{l}\text { Analysis of a sample taken from a wound diagnosed with } \\
\text { leishmaniasis }\end{array}$ & $.885^{\star}$ & $.795^{*}$ & $.003^{\star *}$ & $.167^{*}$ & $.963^{*}$ \\
\hline Blood test is necessary for the diagnosis of leishmaniasis & $.331^{*}$ & $.945^{*}$ & $.004^{* *}$ & $.511^{*}$ & $.670^{*}$ \\
\hline \multicolumn{6}{|l|}{ IV. Treatment } \\
\hline Treatment of leishmaniasis is available & $.716^{*}$ & $.966^{*}$ & $.006^{* *}$ & $.158^{\star}$ & $.566^{*}$ \\
\hline Treatment of leishmaniasis is available in our city & $.528^{*}$ & $.608^{*}$ & $.008^{* *}$ & $.067^{\star}$ & $.123^{*}$ \\
\hline Injection at the wound site one of the treatments of Leishmaniasis & $.962^{*}$ & $.838^{*}$ & $.057^{*}$ & $.862^{*}$ & $.880^{*}$ \\
\hline \multicolumn{6}{|l|}{ V. Prevention } \\
\hline Flypapers can be used to control sand flies & $.461^{*}$ & $.112^{*}$ & $.018^{*}$ & $.332^{*}$ & $.787^{*}$ \\
\hline Insecticides sprays can be used to control sand flies & $.680^{*}$ & $.364^{*}$ & $.026^{*}$ & $.193^{*}$ & $.568^{*}$ \\
\hline Insect repellents can be used to control sandflies & $.510^{*}$ & $.369^{*}$ & $.060^{*}$ & $.686^{*}$ & $.730^{*}$ \\
\hline \multicolumn{6}{|l|}{ VI. Vaccination } \\
\hline Is there any vaccination available? & $.859^{*}$ & $.079^{*}$ & $.002^{* *}$ & $.151^{*}$ & $.821^{*}$ \\
\hline
\end{tabular}


In the present study, sources of facts were mostly friends, family, and relatives, while the role of newspapers, $\mathrm{tv}$, radio, and that of doctors in this regard was found to be limited. This effect is not consistent with the findings of other studies conducted on dengue and malaria.

\section{Recommendation}

Increase outreach programs must be introduced for health training related to leishmaniasis, particularly in rural areas of Pakistan. Distinctive attention must be given to the role of sand-fly as a vector and the recognition/ identification of sand-flies. The role of animal reservoirs in the spread of leishmaniasis must be highlighted.

\section{Limitations}

The present study had various limitations. Since the study was performed only in one town Quetta, Pakistan, and covered 387 respondents using a convenient sampling method, the results may not be accurately illustrative of all the endemic areas in Pakistan. Due to the lack of time and funds, it was infeasible to include the entire Pakistani community in the study. Still, it was a cross-sectional study so it might not, therefore, be compared with the non-prevalent areas.

\section{CONCLUSION}

The findings of the existing survey discovered improved knowledge amongst the public about sandflies, leishmania disease, causative agents of infection, signs, symptoms, diagnosis, treatment, prevention, and vaccination. Possibly, this was due to the sample being from an urban area. The above observations may also be applicable only for the study population of one town because of a convenience pattern and cannot be comprehensive to other people belonging to different cultural or socio-economic settings.

\section{CONFLICT OF INTEREST}

The authors have no conflict of interest to declare.

\section{ACKNOWLEDGEMENT}

We acknowledge the study respondents for their contribution.

\section{Ethical approval}

Informed written consent was obtained from all the respondents after a full clarification of the nature, purpose, and techniques of the study.

\section{REFERENCES}

1. Torres-Guerrero E, et al. Leishmaniasis: A review. F1000 Research. 2017;6(750).

2. Organization WH. Kala-Azar elimination programme: Report of a WHO consultation of partners, Geneva, Switzerland; 2015.

3. Organization WH. Visceral leishmaniasis: Control strategies and epidemiological situation update in East Africa: Report of a WHO bi-regional consultation Addis
Ababa, Ethiopia; 2015.

4. McCall LI, Zhang WW, Matlashewski G. Determinants for the development of visceral leishmaniasis disease. PLoS Pathogens. 2013;9(1):1-7. doi: 10.1371/ journal.ppat.1003053 PMID 23300451.

5. Ready PD. Epidemiology of visceral leishmaniasis. Clinical Epidemiology. 2014;6:147-54.

6. Claborn DM. The biology and control of leishmaniasis vectors. Journal of Global Infectious Diseases. 2010;2(2):127-34.

7. Ghazanfar M, Malik M. Sandfly and leishmaniasis: A review. J Ecosys Ecograph. 2016;6(3):1-5.

8. Magill AJ. Epidemiology of the leishmaniases. Dermatologic Clinics. 1995;13(3):505-23.

9. Rahim F, et al. An outbreak of Cutaneous Leishmaniasis in a village of district Dir, NWFP. Journal of Postgraduate Medical Institute. 2003;17(1):85-9.

10. Kakarsulemankhel JK. Present situation of cutaneous leishmaniasis in Balochistan, Pakistan. Pak J Biol Sci. 2004;7(5):698-702.

11. Bhutto AM, et al. Detection of new endemic areas of cutaneous leishmaniasis in Pakistan: A 6-year study. International Journal of Dermatology. 2003;42(7):543-8.

12. Ejaz A, et al. Outbreak of cutaneous leishmaniasis in Somniani, Balochistanimplementation of preventive measures for deployed personnel of armed forces. Journal of Pakistan Association of Dermatology. 2016;18(4):220-5.

13. Ayub S, et al. Profile of patients of cutaneous leishmaniasis from Multan. JournalPakistan Medical Association. 2001;51(8):279-81.

14. Organization WH. The leishmaniasis. Report of a WHO Expert Committee, Geneva. WHO Tech Rep Ser. 1984;701:1-139.

15. Noor SM, Hussain D. Cutaneous leishmaniasis in Sadda, Kurram agency, Pakistan. Journal of Pakistan Association of Dermatology. 2017;14(3):114-7.

16. Rowland $\mathrm{M}$, et al. An outbreak of cutaneous leishmaniasis in an Afghan refugee settlement in north-west Pakistan. Transactions of the Royal Society of Tropical Medicine and Hygiene. 1999;93(2):133-6.

17. Ali $\mathrm{N}$, et al. Species composition and activity patterns of sand flies (Psycodidae: Phlebotomine) in four tehsils of Dir Districts, Khyber Pakhtunkhwa, Pakistan. Acta Tropica. 2016;156:144-51.

18. Siddiqui $\mathrm{N}$, et al. Awareness about kala-azar disease and related preventive attitudes and practices in a highly endemic rural area of India. Southeast Asian Journal of Tropical Medicine and Public Health. 2010;41(1):1-12.

19. Saleh F, Khan MF, Kabir MR. Awareness of residents about kala-azar and its related practices in two endemic areas of Bangladesh. PloS One. 2019;14(7):1-15.

20. Weerakoon $\mathrm{SH}$, et al. Knowledge on leishmaniasis among health care workers in an endemic area. Anuradhapura Medical Journal. 2016;10(1):6-10.

21. Amin TT, et al. Public awareness and attitudes towards cutaneous leishmaniasis in an endemic region in Saudi Arabia. Journal of the European Academy of Dermatology and Venereology. 2012;26(12):1544-51.

22. Berhe M, et al. Knowledge Attitude and Practice towards Visceral Leishmaniasis among Residents and Health Professionals in Welkait District, Western Tigray, Ethiopia. J Trop Dis. 2018;6(1):4-11.

23. Akram A, et al. A cross-sectional survey of knowledge, attitude and practices related to cutaneous leishmaniasis and sand flies in Punjab, Pakistan. PloS One. 2015;10(6):1-8.

24. Koirala S, et al. Knowledge, attitudes, and practices about kala-azar and its sandfly vector in rural communities of Nepal. Bulletin of the World Health Organization. 1998;76(5):485-90.

25. Singh RH, Pandey HP, Sundar S. Visceral leishmaniasis (kala-azar): Challenges ahead. Indian Journal of Medical Research. 2006;123(3):331-44. 